\title{
ATRIBUIÇÃO DE NOMES PRÓPRIOS E SEU PAPEL NO DESENVOLVIMENTO SEGUNDO O RELATO DOS NOMEADOS
}

\author{
Elaine Pedreira Rabinovich ${ }^{1}$ \\ Daniela Trovaglini ${ }^{2}$ \\ Anna Crisíina Pereira Hulle Coser ${ }^{2}$ \\ Eloane Neves Esteves ${ }^{2}$
}

RABINOVICH F. P. et al. Atribuiição de nomesa próprios e seu papel no desenvolvimento segundo o relato dos nomeados. Rev. Bras. Cresc. Des.. Human, São Paulo. III(2), 1993.

Resumo: O presente estudo replica e amplia a pesquisa anteriormente realizada por Rabinovich et al (191), sobre o processo de nomeação de crianças tendo como base agora a fala de sujeitos adultos sobre o próprio nome. As categorias ptopostas foram validadas e ampliadas. Concluiu-se que o nome, enquanto "script" outorgado pelos pais, indica, entre outros fatores, o futuro papel do nomeado no seu contexto familiar e social, sendo essa influência, em grande parte, desconhecida do nomeado.

Palavras chave: nomes próprios, nomeação.

Sumary: This study replicates and enlarges thw research by Rabinovich et al (1991) on child naming own asking 100 adults suhjects about their names and naming. The previous cathegories were validated. It was concludid that naming may be considered a script given by parents to their children this script may indicate the future social and familiar role of the named person although this influence is, at most, unknown to the subject.

Key words: first names, naming.

\section{INTRODUÇÃO}

Em palestra intiulada "A morte do sujeito", proferida no Instituto dc Psicologia da Universidade de São Paulo (13/05/1992),Agnes Hcller afirmou não haver cultura sem nome. O nome, segundo ela, em contexto com outros nomes, identi- fica a pessoa, não havendo sociedade no mundo em que as pessoas nao sejam distintas umas das outras pelo nome. A identificação, para ela, seria dada pelo "olhar que nomcia" dos outros.

O nome é uma característica presente e enfatizado em todas as culturas. Conforme dizem CHEVALIER e GHEERBRANT (1991),

Contribuiram para a coleta e discussão dos dados Vera Lúcia Ehlers Villele Verônica Stangler Kraemer e Ana Emília F. Mac Dowell, Instituto de Psicologia/USP.

2 Psicologa Clínica, Mestre em Psicologia, pesquisadora do CDH e bolsista CAPES.

3 Alunos do lnstituto de Psicologia/USP 
Adão foi encarregado de nomear os animais e isto concedeu-lhe poder sobre eles (G 2,9). A invocação do nome, segundo esses autores, evocaria o próprio ser, o nome pessoal sendo bem mais que um signo de identificação: seria uma dimensão do indivíduo.

Para MARTINS (1991), o estudo do nome é interdisciplinar por situar-se na fronteira da elaboração do natural em direção ao cultural, já que é recebendo um nome que algo se torna um objeto cultural no circuito maior da sociedade, por intermédio da linguagem. "O nome próprio é mais que um signo ou significante: ele é um texto”.

Estudando o mito de Édipo, VOLPI (1990) menciona que o homem está lançado no palco de sua existência buscando realizar continuamente um "script" que lhe foi entregue na entrada do teatro de sua vida, ou mesmo antes. Participar deste Drama é reconhecer-se integrante de uma trama cujo sentido escapa sempre; é entrar numa "fala" dada por outrem, estruturada ao longo das gerações e transmitida pela linguagem e pela rede de papéis sociais. Inconsciente e destino podem scr entendidos como sinônimos, no sentido de que o inconsciente é vivido como um destino obscuro e desconhecido. Já MARTINS lembra que "o nome não é um destino, uma vez que o sujeito pode vir a escolher um outro destino para si”. Esta questão já havia sido levantada por ABRAHAM (1961) que ao defender a idéia de que o nome contribui para determinar a maneira de ser das pessoas, a contrapõe à concepção de que o nome obrigaria a um determinado destino (op. cit.).

Para MARTINS o nome, embora sem ser um destino, é portador de desejos e da trama simbólica urdida em torno de cada sujeito. " O inconsciente pesa sobre o nome de cada um, infiltrandose na urdidura das letras e dos significados do nome. O nome próprio é suporte da representação psíquica primária. Esta é fruto do desejo de um outro e funciona como uma fantasia inconsciente fabricando sentido.” (MARTINS, 1991).

Esse "texto", que o nome significa, é recebido, sendo a expressão do desejo de um outro. O segundo "parto", que é o nascimento do sujeito para si, para os outros e para a sociedade, se daria pela fala: a "parição" de um sujeito articulado em uma genealogia e num discurso que o sustenta. "O nome próprio é a própria expressão da existência da intersubjetividade e do inconsciente. Ele é mensagem e mensageiro de mitos que são transmitidos de geração em geração. Ele é também pura virtualidade enviando através das associações múltiplas ao universo do sujeito. Este aspecto transgeracional é marcado essencialmente pela articulação existente entre um nome e o afluxo de impulsões desejantes, que nem sempre estão sob controle voluntário consciente daquele encarregado de fazer a nomeação” (MARTINS, 1991).

Desde o estudo de EAGLESON (1946) e o de SAVAGE e WELLS (1948) os nomes próprios passaram a ser objeto de estudo, principalmente enfocando a questão do nome ser "não usual" (MARCUS, 1976) ou "peculiar" ou "incomum” ou "único" (SCHOMBERG e MURPHY, 1974). Estes estudos, assim como o de HARTMAN et al (1968) apontaram para ajustamentos perturbados a partir de nomes peculiares, enquanto outros estudos (ZWEIGENHAFT et al, 1980) apontam para resultado em direção oposta no caso de mulheres. EAGLESON, aliás, já sugeria que um dos principais fatores para a pessoa gostar ou não do nome é sua individualidade, ou seja, sua capacidade de identificar a pessoa. Considera também em seus estudos que muitos sujeitos nunca haviam pensado sobre seus nomes antcriomente à pesquisa

Segundo KOSKAS (1985), desde a origem, os futuros pais começam a esboçar a escultura e modelagem de sua progenitura, tanto corporal quanto socialmente.

RABINOVICH et al (1991), a partir de um estudo longitudinal com crianças de zero a um ano, abordou a questão do nome através de duas perguntas respondidas pelos pais, visando estudar a dinâmica subjacente ao desenvolvimento da criança: Quem escolheu e o porquê da escolha do nome. Classificou as respostas à primeira pergunta em cinco categorias: mãe, pai, mãe/pai, casal e outros. O conjunto dessas categorias foi denominado contexto. As respostas à segunda pergunta foram classificadas em três categorias: estética, parente e fantasia, que foram denominadas conteúdo.

Segundo esses autores, o nome revelaria tanto o universo relacional dos pais, quanto o contexto situacional onde a criança irá adquirindo a sua personalidade; neste sentido, a análise do nome poderia ser um importante instrumento auxiliar na compreensão da trama de signifcações implicadas nesse contexto e das forças incidindo sobre a psiquê infantil.

Baseados nessa pesquisa, foram feitas diretamente a pessoas já adultas, as mesmas perguntas que haviam sido feitas aos pais de recémnascidos (quem escolheu o nome e o porquê da escolha do nome), acrescidas de outras duas: o que o sujeito acha do próprio nome e a influência do mesmo no decurso de sua vida.

Essas perguntas tiveran como objctivo:

1. Replicar, validar e complementar a pesquisa anteriormente realizada.

2. Avaliar as premissas subjacentes à pergunta sobre o conteúdo do nome. isto é como o 
sujeito interage com o desejo dos pais de acordo com o manifestado no nome

3. Apreender a reacão subjetiva do sujeito ao próprio nome.

\section{MÉTODO}

Através de entrevista semi-estruturada foram feitas a 120 adultos de classe social média e media alta (60 homens e 60 mulheres) as seguintes perguntas:

1. Quem escolheu o seu nome?

2. Por que o nome foi escolhido?

3. O que você acha do seu nome?

4. Como você acha que o seu nome influi na sua vida?

5. Qual o nome de seus irmãos?

As respostas foram transcritas literalmente e posteriormente analisadas em categorias obedecendo de forma geral aos critérios usados por RABINOVICH et ai (1991).

\section{RESULTADOS $^{1}$ E DISCUSSÃO}

\section{Quem Escolheu o Nome?}

As respostas à pergunta "Quem escolheu seu nome?” foram classificadas nas seguintes categorias (Tabela 1):

1. MÃE - quando a mãe escolhe sozinha.

As mães escolheram o nome em 47 dos casos (39\%). Este dado confmrma a pesquisa de RABINOVICH et al (1991) e também a sugestão de CHEVALIER (1991) "quem nomeia tem poder sobre o nomeado”. espelhando a organização familiar na qual a mulher voluntária ou involuntariamente é colocada como dona do filho e, preferencialmente da filha(*).

2. PAI - quando o pai escolhe sozinho.

Em contraposição às mães apenas 20 (17\%) dos pais nomearam seus descendentes.

3. PAIS - quando o casal escolhe em conjunto.

Os PAIS escolheram em 22 dos casos (18\%). A relação hannônica tende a se refletir na escolha do nome do filho confirmando RABINOVICH et al (1991). Este nome pode resultar da combinação de nomes dos pais. Exemplos:

Caso I - Marcel combinação dos nomes do pais Marli e Célio.
Caso 2 - Silvia Helena nome do pai Silvio e da mãe Helena.

Conforme MARTINS (1991) estas formas de fusão e condensacão podem representar o amor dos pais para com aquele filho mas podem indicar também um desejo de continuidade através desses filhos. No caso de Marcel. havia uma expectativa de ser mais do que o pai e a mãe individualmente: "a expectativa do meu pai era de que eu fosse diferente, sempre para mais”. Marcel aparentemente buscava cumprir essa vontade impressa em seu nome.

Na maioria dos casos porém a classificação PAIS se refere a nomes mais neutros com pequena carga projetiva geralmente na eategoria ESTÉTICA.

Caso 3 - Marina. "acho que meu pai e minha mãe porque eles acharam bonito. Estavam entre Fernanda e Marina e escolheram Marina.”

4. PAI/MÃE - o pai ou a mãe da criança escolhe dentro de urna regra pré-estabelecida ou através de um nome composto.

Ocorrerreram 5 dos casos (4\%). Contrapõe à categoria PAIS podendo revelar um estado de desarmonia entre o casal. Exemplo:

Caso 4 - Milena Thais: ' Minha mãe queria Milena. mas meu pai só deixou colocar esse nome se ele colocasse Thais também”.

Caso 5 - Cintia Aline: a mãe escolheu Cintia e seu pai cscolheu Aline e os dois juntos acharam o nome todo bonito.

5. OUTROS - outra pessoa escolhe o nome além dos pais ou em conjunto com eles.

Esta categoria esteve presente em 16 dos casos (13\%). Ela indica a importância de alguém além do casal. O significado desta categoria depende de cada caso específico. Exemplos:

Caso 6 - Claudia Sayuri: "Claudia porque a minha tia achava legal e Sayuri porque é pequeno lírio e a minha avó adora lírio”. Desde os 4 anos com o falecimento da mãe Claudia foi criada pela avó e pela tia. Este caso ilustra uma "coincidência” entre a posse e o nome.

Caso 7 - Patricia: "Estava passando uma novela e a minha irmã deu um escândalo em casa c meus pais mudaram o nome”. Há uma suspeita neste caso de que os pais tenham se omitido frente à responsabilidade de ter o segundo filho, devido aos ciúmes do primeiro.

Caso 8 - Natasha: "Minha avó materna me deu esse nome por causa de uma princesa russa. Eu acho que passa uma personalidade forte”.

1 Os resultados foram analisados pela fónnula 0 - E = $3 \mathrm{~V} \mathrm{E} \mathrm{(Aspey.} \mathrm{1977).} \mathrm{A} \mathrm{presença} \mathrm{de} \mathrm{um} \mathrm{asterisco}$ durante o texto indica resultado significante. 
Neste caso, sendo a avó russa, através do nome Natasha é passada a tradição da familia.

Caso 9 - Dimitri: "Minha avó escolheu esse nome porque tinha tendências comunistas e gosta de tudo referente à Rússia”.

Os dois últimos exemplos demonstram a influência da avó sobre o casal, atingindo a criança.

6. COLETIVO - quando um grupo, que pode ou não ter uma rotação de parentesco com os pais, escolhe. Esta categoria está sendo proposta neste trabalho.

Representa 3 dos casos (3\%). Esta maneira de nomear pode indicar uma dificuldade de “corporificacão” dos pais, que pode ser transmitida para o sujeito como uma dificuldade de assumir responsabilidades, quer sociais, quer sobre seus desejos. Exemplos:

Caso 10 - Alexandre Augusto: “A família fez uma lista com vinte nomes para menina e dez para menino, quando nasci colocaram os dois primeiros nomes mais votados na lista".

Caso 11 - Armando: “Aos seis anos, no dia do meu batizado, sorteei meu nome de uma urna onde os familiares haviam colocado as sugestões”.

7. NÃO SABE - quando o entrevistado não tem conhecimento de quem o nomeou.

Esteve presente em 7 dos casos (6\%), havendo cinco homens para duas mulheres que desconheceram a origem da nomeação.

\section{Razões da Escolha}

As respostas à segunda pergunta "por que seu nome foi escolhido?”, foram classificadas em seis categorias (Tabela 2):

\section{ESTÉTICA - "porque é bonito"}

Foi a categoria de maior frequência, atingindo 37,5* (31\%). Esta categoria pode estar camuflando outras, denotando apenas o desconhecimento dos próprios pais sobre os motivos que os levaram à escolha do nome 27 (45\% ) de nomes de mulheres estão nesta categoria para 10,5 (17\%) de homens.

2. FANTASIA - nomes de personagens históricos, bíblicos, de novelas, filmes, livros, músicas, nomes de atores, etc, além do próprio significado do nome. Do mesmo modo que a anterior, esta categoria se concentra em nomes femininos. Representa 27,5 (24\%) dos casos em geral e 18 (30\%) das mulheres. Exemplos:

Caso 12 - Aline: "Tinha uma música que minha mãe adorava e chamava Aline”.

Caso 13 - Luthero: "Minha mãe queria que eu fosse pastor e me deu o nome de Luthero".

Há também o caso particular do significado do nome, que pode acarretar ou não consequências em funcão do nome ser um símbolo
Exemplos: Angela, Lilian, Salma, Estela, Alegria, Esperança, etc.

Caso 14 - Estela: “minha mãe queria que eu fosse uma estrela, que eu tivesse um brilho que eu nunca consegui ter".

Caso 15 - Salma: "Traduz a maior característica da minha personalidade - a alegria”.

A categoria parente da pesquisa de RABINOVICH et al (1991) foi, neste trabalho, subdividida em TRADIÇÃO, HOMENAGEM e IRMANDADE.

3. TRADIÇÃO - “Através da transmissão de uma geração à outra por intermédio da linguagem, a pessoa passa a estabelecer uma filiação de ordem cultural familiar onde o desejo se inscreve” (MARTINS, 1991). Quanto mais rígida for a tradição, maior será a exigência sobre a criança. Esta categoria se diferencia da HOMENAGEM justamente por estes aspectos. Ambas servem para homenagear, dar prestígio e fortalecer laços, contudo, na categoria TRADIÇÃO a função da linhagem é muito enfatizada, enquanto que na categoria HOMENAGEM o conteúdo afetivo é mais forte.

Caso 16 - Afonso: "Foi meu tio paterno, porque era o nome do meu avo paterno, e ele queria que eu continuasse esse nome” (TRADIÇÃO). Caso 17 - Raimundo: "Meu pai escolheu o nome do meu avô como uma forma de dar continuidade e homenagear alguém da familia” (TRADIÇÃO/ HOMENAGEM).

Caso 18 - Lilian: "Minha mãe não engravidava, mas ficou grávida com um médico. Se fosse menino teria o nome do médico, mas como foi menina teve o nome da mulher do médico..."(HOMENAGEM)

HOMENAGEM/TRADIÇÃO significa a força da linhagem e da estrutura de parentesco. A pessoa que é nomeada desta maneira geralmente tem uma responsabilidade de corresponder à essas expectativas.

As categorias HOMENAGEM e TRADIÇÃO correspondem, respectivamente, a 14 (12\%) e 18 (15\%) dos casos. Na categoria TRADIÇÃO predominam os nomes masculinos: 16 em 18 nomes representando $27 \%$ do total dos nomes masculinos.

4. NÃO SABE - desconhccc a razão da nomeação. Assim como a categoria NÃO SABE da primeira pergunta, 9 homens para 2 mulhercs não sabem a origem do nomc.

5. IRMANDADE - é um tipo especial de TRADIÇÃO em que o nome é escolhido segundo uma regra de nomeação dos filhos. Essa regra pode ser pela inicial, pela repetição de um mesmo nome (ex: Luiz Roberto e Luiz Eduardo) ou pela combinação dos sons dos nomes (ex: Luciana e Tatiana). Presente em 4,5 (4\%) dos casos. 
Caso 19 - Tatiana: "meu pai queria um nome russo que combinasse com Luciana, o nome da minha innã".

Caso 20 - Roberto: "meu pai chama Rubens, meu irmão mais velho Ricardo e o irmão que morreu com poucos dias chamava Renato. Eu sou chamado pelo sobrenomc".

Esse caso ilustra a força da origem paterna. não apenas pela inicial, mas também pelo uso do sobrenome no lugar do nome. Roberto seguiu a profissão do pai, assim como seu irmão.

A classificação IRMANDADE parece indicar que os pais ou iniciam ou dão continuidade a uma "produção". Os nomes são como marcas que rcforçam o clã e a união familiar. No caso de Tatiana c Luciana, as irmãs, com um ano de diferença entre seus nascimentos, comportam -se como se fossem gêmeas idênticas.

6. ACASO - É a escolha do nome por um processo aleatório. Esta categoria demonstra a "não elaboração" na escolha do nome. Através dos dados obtidos foi observada a vinculação desta categoria com o COLETIVO da primeira pergunta (3 casos 3\%).

7. SOCIAL - O nome é dado em função de uma significação social. Trata-se de um caso cquivalente à moda (por nós classificada em Esletiea ou Fantasia), porém com referêencia a alguma etnia ou grupo social. Ocorreu em um caso.

Caso 21 - Maria Helena: "não queriam que eu me chamasse Ingrid, um nome alemão, por causa da guerra”.

Essa categoria articula a trama pessoal, familiar e social quc está necessariamente presente em lodos os casos.

\section{Avaliação do Nome}

Embasando-se na terceira pergunta "o que você acha do seu nome?” foram obtidas as seguintes categorias (Tabela 3 ):

1. BOM - o sujeito gosta do nome. A maioria dos entrevislados se encontra nessa categoria, 79,5 (66\%) Exemplo: Caso 22 - $\mathrm{Chr}^{\wedge}{ }^{\wedge} \wedge^{\wedge} \mathrm{sl} \wedge$ iane: "Acho lindo! Adoro! Não trocaria”.

2. CRÍTICA - o sujeito descreve características tanto positivas quanto negativas do nome 21 (17\%). Houve um predomínio dc mulheres nessa categoria. (14,5 mulheres para 6,5 homens)

Caso 23 - Luciane: “Acho bonito, forte, mas seco".

3. COMUM - representado por um nome que é frequente na população. Aparece descrevendo o nome de $9(10,2 \%)$ entrevistads.

Caso 24 - Ana Cristina: "Não cria problemas”.

Caso 25 - Ana Maria: "Comum. Não me identifica. Preciso complementar com o sobrenome ou com mulher do fulano”.
Na maioria dos casos o COMUM vem associado ao BOM, porém, determinando uma característica negativa:

Caso 26 - João de Deus: "Acho bem brasileiro, mas acho fácil achá no cartório vários sujos na praça: (com o mesmo nome dele), mas eu gosto”.

4. RUIM - o sujeito não gosta do nome. É representada por $6(5 \%)$ dos sujeitos.

Caso 27 - Neusa Maria: “Acho nome de empregada, nunca gostei."

MARTINS (1991) comenta que a apreciação positiva ou negativa do nome influencia o modo como a pessoa c julgada pelos outros, o que, por sua vez, tem um impacto sobre a autoestima. Nomes não usuais apareceriam relacionados a pessoas desajustadas (SAVAGE e WELLS, 1948; MARCUS, 1976; ANDERSON, 1989). Contudo, esse mesmo autor, assim como o próprio SAVAGE et al (1948), SCHOMBERG et al (1974) e SWEINGENHAFT et al (1980), Iembra que o nome único comporta possibilidades positivas, o que foi por nós várias vezes evidenciado: o nomeado tem orgulho do seu nome queo identifica c personaliza.

Caso 28 - Eloane: "Eu gosto porque cria uma coisa única que eu posso ser”.

5. ADAPTAÇÃO - Ncsta categoria se enquadram os sujeitos que declararam ter mudado sua opinião em relação ao nome, passando a gostar do mesmo (4\%, 4,5 casos).

Segundo MARTINS (1991) resolvendo o seu nome a pessoa resolve conflitos essenciais latentes que muitas vezes se prolongaram desde a primeira infância Para esse mesmo autor a adolescência marca um processo de estabilização das identificações do adulto jovem podendo o nome tornar-se também um obstáculo o que não ocorreu em nossa pesquisa onde esta mudança ocorreu "positivamente" num encontro da pessoa consigo própria. Exemplos

Caso 29 - Irene "teve uma época que eu não gostava depois aprendi a gostar pelo fato de ter sido meu pai que escolheu”.

Caso 30 - Gemma Eleonora "O nome foi escolhido pela minha mãe ... Hoje estou acostumada apesar de causar surpresa a todos”.

Para MARTINS (1991) o desejo de quem nomeia pode ser concebido como um investimento narcísico do próprio Eu no mundo exterior. “Do ponto de vista interior daquele que relata sua história o nome próprio é muito mais que um signo referencial. Além de permitir a identificação no mundo exterior do indivíduo o sujeito se identifica a ele. Isso implica em uma "vasta aprendizagem" que é um movimento de revelação para o sujeito daquilo que ele é sem o saber de forma 
prévia. É muito mais uma descoberta do quanto o sujeito se identifica com determinadas figuras” (MARTINS 1991). Neste movimento identificatório dois eixos de análise aparecem. São eles a identificação imaginária e a simbólica. A imaginária se nutre e enraiza na vida de fantasia do sujeito Ela está relacionada com o Eu enquanto objeto. Já a identificação simbólica ancora o sujeito no campo do símbolo através sobretudo da constituição do ideal do Eu.

Conforme um movimento de revelação a pessoa irá aceitando ou não seu nome identificando-se ou não quer com seu próprio Eu quer com seu ideal de Eu. Deste modo explicam-se as categorias acima descritas

\section{Influência Atribuída ao Nome}

Através dos dados obtidas à quarta pergunta "como você acha que seu nome influi na sua vida?” chegamos a cinco categorias (Tabela 4).

1. POSITIVA - o sujeito admite a influência sendo esta benéfica 47,5 (40\%).

Caso 4 - Claudia Sayuri: “O nome é um cartão de visitas e o meu é apresentável”.

Quase todos os casos POSITIVA mostran uma identificacão da pessoa com o nome. A pessoa incorpora o próprio nome, não se imagina com outro. Este marca sua individualidade ilustrando a afirmação de CHEVALIER (1991) “o nome é uma dimensão do indivíduo” A consciência da importância do nome é observada nestes sujeitos. Exemplos:

Caso 34 - Luiz Guillherme "O Guilherme com certeza tem a ver com a grande admiração pelo meu pai mas o Luiz garantiu a minha individualidade".

Caso 29 - Irene "Eu acho que meu nome é simples como eu, cai muito bcm com a minha pessoa”.

2 NEGATIVA - o sujeito admite a influência sendo esta de alguma forma prejudicial. Aparece em 13,5 (11\%) dos casos. Exemplos:

Caso 31 - Claudio "Não foi importante para mim, só para a minha "mãe”.

Caso 32 - Daniela "Só atrasou minha vida".

3 NENHUMA - o sujeito declara que não existe influência (39\%, $N=47)(*)$ Exemplo:

Caso 33 - Marina "Eu não acho que influi o fato de eu me chamar Marina, Fernanda ou Carolina"

4. NÃO SABE (10\%, $\mathrm{N}=12)$.

O sujeito ignora se existe ou não influência

Essas categorias podem ser divididas $\mathrm{cm}$ dois grandes grupos

1. INFLUENCIA (51\%) positiva e negati-

\section{NAO INFLUENCIA (49\%) nenhuma e} não sabe.

De um modo geral o que os sujeitos demonstram quando admitem a influêneia e conhecer a relação entre nome e identidade seja ela positiva ou negativa. Porém desconhecem em geral a dinâmica subjacente ao processo de nomeação e sua influência sobre a própria constituição da identidade da pessoa.

\section{Conhecimento da Influência do Nome}

Muitas pessoas acham que o nome não tem influência, porém algumas têm noção desse conteúdo:

Caso 35 - João de Deus. "Influi tanto quanto minha vida. Até esta idade graças a Deus estou trabalhando com saúde (conteúdo religioso). Quem sabe se eu tivesse um nome mais bonito. $\mathrm{O}$ nome é um signo".

Caso 36.- Juliana: "Acho que combina comigo. Acho que passa um estado de espírito, é alegre, mas o alegre é meio subjctivo meu. Se fosse Júlia... Júlia é um nome pesado e Juliana é cheia de juventude. Se eu fosse Júlia, teria de assumir uma postura mais séria”.

Caso 37 - Betina: “A gente escuta comentários de que o nome é diferente e acaba se sentindo muito especial”.

Caso 38 - Sérgio Fernando: “Acho que é a base sobre a qual reconstruo a minha pessoa”.

Caso 39 - Andre Luiz (conteúdo religioso, FANTASIA): "influencia porque é o número 8, é a matéria, e eu sou comerciante”.

Caso 40 - Federico: "Por ser um nome diferente comecei a pensar diferente.

Caso 41 - Arnaldo Augusto: "Acho legal. Tenho sido confundido com meu pai c isso não me faz mal porque ele é uma pessoa correta e eu me orgulho dele (...). Interfere ainda que inconscientemente até na profissão porque a família do meu pai é de médicos como eu (...). Dá idéia de que faz tempo que tem pessoas corretas na família c eu sou carreto".

Segundo este tipo de Ieitura pode-se perceber que a questão subentendida c a da identificação pelo e com o nome: tanto o nome pode identificar ou não, quanto a pessoa pode se identificar com o nome ou não.

Em alguns relatos pode-se observar que a pessoa forneceu indicacões sobre a importância c a influência do nome sem, contudo, ter consciência do que fazia. Exemplo:

Caso 42 - Débora Irene: "Não tem nenhuma influêneia. Acho forte c bonito, bem forte. Débora. Levar o nome da minha avó não interfere em nada mas toda vez que toco no meu nome Iembro-me dela”. 
Este discurso nos revela que, de início, o sujeito diz que o seu nome não tem influência mas, em seguida, nega o que acabara de enunciar, colocando que o seu nome é forte. A nível consciente, o dcpoente pode não associar o caráter forte do nome a qualquer influência, mas, o simples fato dele enunciar tal ordem de idéias indica a associação entre dois exertos de fala, o que, do ponto de vista psicanalítico, indicaria estar um cxerto associado ao outro. Em seguida, nega novamente a idéia da não influência de modo mais flagrante, ao associar seu nome ao da avó, que é por ela recordada cada vez que ela é denominada, ou seja, haveria uma confluência entre a sua identidade e a lembrança da avó.

Da Ieitura de alguns nomes pelos pesquisadores foi possível Ievantar a hipótese de que a fala pode revelar conteúdos inconscientes, não cxplícitos para o sujeito mas dedutíveis de sua fala pelo outro. Retornamos, pois, ao campo, com hipóteses sobre a influência de alguns desses nomes:

Caso 1 - Angélica: "Quando nasci, minha pele era muito clara e lembrava um anjo... Acho que é um bom nome que acabou combinando de certa forma com meu tipo de pele, olhos claros e cabelos claros”. Retorno: Você se identifica com um anjo?

Angélica: "Eu acho que sou uma anjo, exijo demais de mim, minha mãe mesma diz, todo mundo diz que eu preciso dar um tempo."

Caso 2 - Vera Lúeia: "O nome foi escolhido porque era de uma menina que fazia companhia para minha mãe, e o pai gostava do signifcado do nome - verdadeira luz do amanhecer”.

A hipótese era de que existia uma expectativa que a criança viesse a preencher a solidão dos pais, principalmente da mãe, e foi confirmada, após perguntar-se aos pais da nomeada. Esta estrutura de apego perpetuou-se da família de origem para a sua descendência, segundo relato da nomeada.

Caso 3 - Anna Cristina: O nome foi escolhido em função de um eoncurso de beleza.

Retorno: Qual a importância da questão estética na sua vida? Anna Cristina: "Nossa, eu fui Miss."

Esses exemplos ilustram a força modeladora subjacente à eseolha, ou seja, os fatores que levaram os pais a escolher um dado nome também atuaram, no sentido de fazer o filho se dirigir àquela direção. Ilustram a trama do simbólico sobre o “segundo parto” e a inconsciência dos nomeados quanto a isso.

\section{Tipos de Nomeação}

Conforme já foi dito, na maioria dos casos a mãe é quem eseolhe o nome dos filhos. A cate- goria preferida pelas MÃES para escolher o nome das filhas recai em ESTÉTICA e FANTASIA, assim como quando a escolha é feita pelo PAI para as filhas, enquanto que para os filhos homens, os PAIS, o PAI e a MÃE preferem a categoria TRADIÇÃO. (Tabela 5)

Não foi encontrado nenhum caso de escolha ESTÉTICA do PAI para um filho homem, assim como do TRADICÃO do PAI para filha mulher. Já a MÃE escolheu dois nomes compostos para filhas por TRADIÇÃO. Todos esses casos apontam para diferenças sociais associadas ao gênero.

Partindo da hipótese de que os nomes são a projeção dos desejos (conscientes e inconscientes) dos pais nos filhos, nota-se que a escolha da TRADIÇÃO para os filhos homens mostra as expectativas dos pais quanto à continuidade da família enquanto que para as filhas o projetado é ESÉTICA e FANTASIA, um ideal ligado à atratividade e a emotividade. Desse modo, podese pensar haver um tipo de nomeação feminino c um tipo de nomeação masculino, provavelmente associado à valoração atribuida a cada um dos gêneros.

Observou-se anteriormentc a predominância das categorias NENHUMA e POSITIVA na pergunta sobre a influência do nome, Na tabela 6, pode-se ver que a maioria das pessoas destas categorias gostam de seu nome.

A categoria BOM foi aparentemente usada para encobrir a indiferença ante o nome, o que aparece na alia relação entre as eategorias BOM/ NENHUMA e BOM/NÃO SABE.

Quanto à influência NEGATIVA, ela se correlaciona com as categorias RUIM e CRÍTICA, porém apenas homens acham o nome RUIM/ NEGATIVO enquanto a categoria CRÍTICA se associa à influência NEGATIVA principalmente em mulheres. Com essa diferença entre gêneros, pode-se concluir que quando a pessoa não gosta de seu nome ele influencia negativamente em sua vida, mas as mulheres resistem em assumir tal influência.

A categoria COMUM aparece muitas vezes correlacionada à categoria NENHUMA influência, o que pode indicar uma indiferença ao próprio nome, em oposição às duplas POSITIVA/ BOM ou NEGATIVA/RUIM; Pode-se, pois pensar haver tipos POSITIVO NEGATIVO e INDIFERENTE em relação ao nome, referidos tanto à avaliação quanto à influência do nome segundo o nomeado. Haveria uma diferença de gênero no tipo NEGATIVO enquanto as mulheres criticam seu nome, os homens assumem não gostar dele.

De um modo geral, pode-se dizer que quando há acordo entre o casal quanto ao nome, ao 
mesmo tempo em que o casal em conjunto escolhe, parece ocorrer uma facilitação no sentido de o nomeado ineorporar o seu nome, aceitando-o e sendo por ele identifcado, enquanio situações de conflito apontam para a direção oposta.

Há casos em que o nível de eonflito é tão intenso (COLETIVO ACASO) em que parece ocorrer o que KOSKAS (1985) denominou a "paralisia dos escultores". A desistência ou transferência da responsabilidade do casal pelo filho parece gerar um processo de "desinvestimento" afetivo do nomeado em relação ao próprio nome, o que levaria ao uso de um apelido ou do sobrenome como substituto do nome. Esta mesma dinâmica, de modo mais mitigado, pode ser apreendida em várias pessoas quer ao mesmo tempo que desconheciam a origem e a influência do nome, não tinham problemas com o nome e o achavam comum ou bom. As pessoas para quem o nome tem uma signifcação maior, têm usualmente conhecimento da origem de seus nomes e se posicionam, favorável ou desfavoravelmente a eles. Desse modo, parece-nos que, quando se pesquisa o nome a partir do adulto, pode-se apreender algo do inter-relacionamento do sujeito com seus pais.

Podemos supor dois tipos de investimento no próprio nome: o investido e o desinvestido, com graduação entre eles. Esta tipologia estaria relacionada à questão da identidade construída a partir da relação com o contexto sócio-familiar.

Observando-se as categorias do conteúdo e a influêneia/avaliação dos nomes, parece haver um tipo TRADIÇÃO/POSITIVO maseulino, em que os homens gostam e são influenciados positivamente ao receberem nomes de antepassados (vide caso 41).

\section{CONCLUSÃO}

As categorias de conteúdo e contexto propostas pelo estudo antcriormente realizado (RABINOVICH et al, 1991) foram mantidas e ampliadas. As categorias de contexto, mãe, pai, pais, pai/mãe, outro, foi acrescentada à categoria coletivo. A categoria de conteúdo parente foi subdividida em três novas categorias: tradicão, homenagem e irmandade, acrescentando-se ainda as categorias originalmente propostas, estética e tradição, às novas categorias acaso e social.

Foram confirmadas também as principais conclusões do estudo supracitado: a dinâmica familiar e as expectativas/desejos parentais formam um contexto de desenvolvimento com o qual o neonato irá interagir, e que pode ser apreendido, em parte, pelo estudo do processo de nomeação
No processo de nomeação, pode-se perceber e inferir o modo como a pessoa foi inserida como ser social no contexto onde irá se desenvolver.

As crianças teriam, ao nascer, papéis préestabelecidos pela sociedade, endossados e interpretados pelos pais em “scripts” individualizados segundo o tipo de avaliação e o tipo de expectativas destes com relação à criança. Pode-se verificar que o papel social influencia no processo de escolha do nome e no próprio nome.

Do ponto de vista macro-social, observouse uma primeira e ampla especificação por gênero, isto é, meninos recebem nomes masculinos e meninas, nomes femininos. Embora haja nomes que se adequem a ambos os sexos, em nossa pesquisa $100 \%$ dos nomes foram claramente de homens ou de mulheres.

Meninas receberam prcferencialmente nomes por estética e fantasia, dados na maioria das vezes por suas mães, enquanto praticamente só meninos receberam nomes ligados à tradição familiar. Isso parece indicar que às mulheres, em nossa sociedade, cabe o papel da atratividade, enquanto os homens são responsabilizados pela continuidade familiar. Os meninos, além disso, receberam nomes que indicam o desejo dos pais de que seus filhos ocupem posições de poder na sociedade, o que aponta para a perpetuação de papéis reprodutivos e produtivos tradieionalmente ocupados em nossa sociedade por mulheres e homens na própria atribuição dos nomes.

Tal continuidade também pode ser percebida pelo fato de serem as mães a escolherem os nomes dos filhos, o que indica ser ainda a mulher a responsabilizada pelos cuidados da prole em nossa sociedade. Por outro lado, ela escolhe também o nome do filho homem, em conjunto com o pai, o que parece indicar o desejo da mulher de "possuir" o seu filho através do nome. O fato de muitos desses nomes confirmarem a tradição familiar em linha patriarcal sugere que a mãe compõe com o pai possivelmente para não perder a posse do filho. A hipótese de que a nomeação apenas pelo pai, sem anuência da mãe, indicaria conflito no casal e possívcis perturbações no desenvolvimento da criança, levantada pelo estudo anterior, não foi confirmada nesse estudo.

Por outro lado, o conteúdo irmandade forneceu indícios de uma estrutura familiar em que os pais colocam o peso da tradição sobre todos os filhos, instituindo uma união, solidariedade e continuidade pela identidade simbolizada no nome.

Com base nesses dados, podemos concluir que pelo nome, a pessoa é inserida no contexto social, tanto familiar quanto da sociedade em geral, ao mesmo tempo que, através dele, constrói a sua identidade. Esta identidade é construída em 
função de um duplo referencial: a pessoa em relação ao grupo e a pessoa em relação a si própria. Conforme a relação da pessoa com o projeto parental e, pressupondo-se a própria relação pais-filho, haverá uma facilitação da incorporação dos conteúdos projetados pelos pais no filho e, desse modo, na relação consigo próprio.

Pudemos verificar que quando a pessoa aceita seu nome e, deduzimos os conteúdos nele implicados, ela gosta de seu nome, é por ele influenciada positivamente e o nome a identifica. Quando a pessoa não aceita o nome ou não gosta do mesmo, é por ele influenciada negativamente, ou, no caso de desconhecer tal influência, acha o nome comum ou ruim c não é por ele identificada.

Desse modo, do ponto de vista do sujeito, a questão mais importante associada ao nome é a da própria identidade: ou a pessoa o assume como

\section{BIBLIOGRAFIA}

ABRAI IAM, K. Sobre el poder determinante de los nombres. In Estudios sobre Psicoanalise y Psiquiatria. Ed. Horme, Buenos Aires. 1961. p. 29-30.

ASPEY, W. P. Wolf Spider Sociobiology: Agonistic Display and Dominance-Subordinance Relalions in Adult Male. Scbizocosa Crassipes. Behavior. LXII: 103-141, 1977.

ANDERSON. T.; SCHMITT, P. R. Unique First Names in Male and Fcmale Psychiatric Patients. Journal of Social Psychology. 130 (6): 835-837, 1989.

BERENSTEIN. 1. Família e doença mental. Editora Escuta, São Paulo, 1988.

CHEVALIER, J.; GHEERBRANT, A. Dicionário de Símbolos. $4^{\mathrm{a}}$ edição, José Olímpio Editora, Rio de Janeiro, 1991.

EAGLESON, O. W. Students's reactions to their givcn-names. Journal of Social Psychology, 223: 187-195, 1946.

HARTMAN A. A.; NICOLAY, R.C.; HURI,EY J. Unique Personal Names as a social adjust- uma marca, ou é por ele marcado, mesmo que através da indiferenciação.

Porém, identificadas ou não, as pessoas usualmente deseonheecm a influência do nome em suas vidas. Conforme MARTINS (1991) “Je est un autrc” (RIMBAUD): somos o pensamento elaborado por outro e desconhecido, em grande parte, por nós mesmos.

Entre a escuta da história do nome e a fala do nomeado há uma lacuna que parece mostrar que o que esta representado no nome é tão constituinte da pessoa que ela não consegue “descolar” o nome de si própria. Tal descolamento é possível através de hipóteses interpretativas que, trazidas à consciência da pessoa, são por ela assumidas como verdadeiras. Desse modo podemos concluir que as pessoas geralmente desconhecem as forças que operam na constituição de sua identidade.

ment factor. Journal of Social Psychology, 76: 107-110, 1968.

KOSKAS, A. Un prénom et un nom pour écrire un corps. 1985. [Comunicado particular].

MARCUS. M. G. The Power of a Name. Psychology Today. October 1976, p. 75-76.

MAR'I'INS, F. O nome próprio. Univcrsidade de Brasília, Brasília, 1991.

RABINOVICH, E. P et al. Atribuição dos nomes próprios de neonatos. Boletim de Psicologia XLI (94/95), Jan - Dez/ 1991.

SAVAGE, B. M.; WELLS, F. L. A Note on Singularity on Given Names. Journal of Social Psychology, 27: 271-272, 1948.

SCHOMBERG, B. M.; MURPHY, D. M. The Relantionship Between the Uniqueness of Given Name and Personality. Journal of Social Psychology, 93:147, 1974.

ZWEIGENHAFT, R. L.; HAYES, K. N.; HAAGEN, C. H. The Psychological Impact of Names. Journal of Social Psychology. 110: 203-210, 1980.

VOLPI, A. J. Edipo, psicodrama do deslino. Agora. São Paulo, 1990; 


\section{ANEXOS}

Tabela 1: Respostas à pergunta: "Quem excolheu o nome?" dadas por homens $e$ mulheres, São Paulo, 1992.

\begin{tabular}{c|c|c|c}
\hline & FEMININO & MASCUIINO & TOTAI \\
\hline MÃE & $27^{*}$ & 20 & $47^{*}$ \\
\hline PAI & 9 & 11 & 20 \\
\hline PAIS & 7 & 15 & 22 \\
\hline PAI /MÃE & 5 & - & 5 \\
\hline OUTROS & 10 & 6 & 16 \\
\hline COLETIVO & - & 3 & 3 \\
\hline NÃOSABE & 2 & 5 & 7 \\
\hline TO'TAL & 60 & 60 & 120 \\
\hline
\end{tabular}

Tabela 2: Respostas à pergunta: "Por que escolheu o nome?" dadas por homens e mulheres, São Paulo, 1992.

\begin{tabular}{c|c|c|c}
\hline & FEMININO & MASCULINO & TOTAL \\
\hline ESTÉTICA & $27,0^{*}$ & 10,5 & $37,5^{*}$ \\
\hline FANTASIA & $18,0^{*}$ & 11,5 & 29,5 \\
\hline HOMENAGEM & 8,0 & 6,0 & 14,0 \\
\hline TRADIÇÃO & 2,0 & 16,0 & 18,0 \\
\hline IRMANDADE & 1,0 & 3,5 & 4,5 \\
\hline SOCIAL & 1,0 & - & 1,0 \\
\hline ACASO & 1,0 & 2,5 & 3,5 \\
\hline NÃOSABE & 2.0 & 10,0 & 12.0 \\
\hline TOTAL & 60,0 & 60,0 & 120,0 \\
\hline
\end{tabular}

Tabela 3: Respostas à pergunta: "O que você acha do seu nome?" dadas por hormens e mulheres, São Paulo, 1992.

\begin{tabular}{c|c|c|c}
\hline & FEMININO & MASCULINO & TOTAL \\
\hline BOM & $35,5^{*}$ & $44,0^{*}$ & $79,5^{*}$ \\
\hline RUIM & 1,5 & 4,5 & 6,0 \\
\hline CRÍTICA & 14,5 & 6,5 & 21,0 \\
\hline ADAPTADO & 3,5 & 1,0 & 4,5 \\
\hline COMUM & 5,0 & 4,0 & 9,0 \\
\hline NÃOSABE & - & - & - \\
\hline TOTAL & 60,0 & 60,0 & 120,0 \\
\hline
\end{tabular}


Tabela 4: Respostas à pergunta: "Como você acha que o seu nome influi na sua vida?" dadas por homens e mulheres, São Paulo, 1992.

\begin{tabular}{c|c|c|c} 
& FEMININO & MASCULINO & TOTAL \\
\hline POSITIVA & $20,5^{*}$ & $27,0^{*}$ & $47,5^{*}$ \\
\hline NEGATIVA & 5,5 & 8,0 & 13,5 \\
\hline NENIIUMA & $27,0^{*}$ & $20,0^{*}$ & $47,0^{*}$ \\
\hline N $\tilde{\text { OOSABE }}$ & 7,0 & 5.0 & 12,0 \\
\hline TOTAL & 60,0 & 60,0 & 120,0 \\
\hline
\end{tabular}

Tabela 5: Cruzamento entre as respostas às perguntas "Quem escolheu...?" $e$

"Por que escolheu...?", São Paulo, 1992.

\begin{tabular}{|c|c|c|c|c|c|c|c|c|c|c|c|}
\hline & Mãe & Pai & \multicolumn{2}{|c|}{ Pais } & \multicolumn{2}{|c|}{$\mathrm{P} / \mathrm{M}$} & \multicolumn{2}{|c|}{ Outros } & Coletivo & Não Salxe & Total \\
\hline & F $\quad \mathrm{M}$ & $\mathrm{F} \quad \mathrm{M}$ & $\mathrm{F}$ & $\mathrm{M}$ & $\mathrm{F}$ & $M$ & $\mathrm{~F}$ & $M$ & $\mathrm{~F} \quad \mathrm{M}$ & $M$ & $M$ \\
\hline ESTÉtICA & $10,5 \quad 2,5$ & $4,5-$ & 2.5 & 4,0 & 3,0 & - & 5,5 & 3,0 & $-\quad 1,0$ & $1,0 \quad-$ & $27 \quad 10,5$ \\
\hline FANTASIA & $10,0 \quad 5,0$ & $2,5 \quad 2,5$ & 1,0 & 2.0 & 1,0 & - & 3,5 & 1,0 & - & - 1,0 & $18 \quad 11,5$ \\
\hline HOMEN. & $\begin{array}{|ll|}4,0 & 1,5 \\
\end{array}$ & $0,5 \quad 2,5$ & 3,5 & 2.0 & - & - & 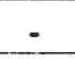 & - & - & - & $8 \quad 6,0$ \\
\hline TRADIÇAOO & $1,0 \quad 4,5$ & - 4,5 & - & 6,0 & - & - & 1,0 & 1,0 & - & & 216,0 \\
\hline IRMAND. & $0,5 \quad 1,5$ & $0,5 \quad-$ & - & 1,0 & - & - & - & - & - & & 13,5 \\
\hline ACASO & 1,0 & $-0,5$ & - & 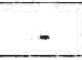 & - & - & - & - & 2,0 & - & 12,5 \\
\hline SOCIAL & - & 1,0 & - & - & - & - & - & 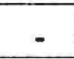 & - & - & 1 \\
\hline NĀo SABE & $\begin{array}{r}-5,0 \\
\end{array}$ & $-\quad 1.0$ & - & - & 1.0 & - & $=$ & 1.0 & - & $\begin{array}{ll}1.0 & 3.0 \\
\end{array}$ & 210.0 \\
\hline TOTAL & 2720 & $9 \quad 11$ & 7 & 15 & 5 & - & 10 & 6 & 3 & 2 & 6060 \\
\hline
\end{tabular}

F - FEMININO; M - MASCULINO; P/M - PAI/MÃE

Tabela 6: Cruzamento entre as respostas às perguntas " $O$ que você acha...?" e "Qual a influência...?", São Paulo,1992.

\begin{tabular}{|c|c|c|c|c|c|c|c|c|c|c|}
\hline & \multicolumn{2}{|c|}{ POSITIVA } & \multicolumn{2}{|c|}{ NEGATIVA } & \multicolumn{2}{|c|}{ NENIIUMA } & \multicolumn{2}{|c|}{ NÃO SABE } & \multicolumn{2}{|c|}{ TOTAL } \\
\hline & $\mathrm{F}$ & $\mathrm{M}$ & $\mathrm{F}$ & $\mathrm{M}$ & $\mathrm{F}$ & $\mathrm{M}$ & $\mathrm{F}$ & $\mathrm{M}$ & $\mathrm{F}$ & $\mathrm{M}$ \\
\hline $\mathrm{BO} M$ & 16,5 & 22,5 & 1,0 & 1,0 & 15,0 & 15,5 & 3,0 & 5,0 & 35,5 & 44,0 \\
\hline RUIM & - & - & - & 3,5 & 0,5 & 1,0 & 1,0 & - & 1,5 & 4,5 \\
\hline CRÍTICA & 3,5 & 3,0 & 2,0 & 2,0 & 7,0 & 1,5 & 2,0 & - & 14,5 & 6,5 \\
\hline ADAPTADO & - & - & 1,5 & 1,0 & 1,0 & - & 1,0 & - & 3,5 & 1,0 \\
\hline COMUM & 0.5 & 1.5 & 1.0 & 0.5 & 3,5 & 2.0 & - & - & 5.0 & 4.0 \\
\hline TOTAL & 20,5 & 27 & 5,5 & 8 & 27 & 20 & 7 & 5 & 60 & 60 \\
\hline
\end{tabular}

F - FEMININO; M - MASCULINO 